Revista de Derecho

de la Pontificia Universidad Católica de Valparaíso

52 (primer semestre de 2019)

[pp. 195 - 224]

\title{
EL IMPUESTO SOBRE LAS EMISIONES DE FUENTES FIJAS Y SU INSERCIÓN EN EL SISTEMA TRIBUTARIO CHILENO
}

[The fixed sources tax and its insertion in the Chilean tax system]

María Pilar Navarro Schiappacasse*

RESUMEN

ABSTRACT

La Ley $\mathrm{N}^{\circ} 20.780$ introdujo en la legislación chilena un tributo que grava las emisiones de fuentes fijas. Este trabajo determina, mediante un análisis dogmático y crítico de dicho tributo, las implicancias aplicativas y los problemas constitucionales que se suscitan a partir de la entrada en vigencia de este gravamen.

\section{Palabras clave}

Derecho Tributario - tributación ambiental - emisiones de fuentes fijas - principios constitucionales - base Imponible.
The No. 20.780 Act introduced into the Chilean legislation a tribute that taxes fixed sources emissions. This paper determines, from a dogmatic and critical analysis of the said tax, the applied implications and constitutional problems that arise from the time this tribute came into effect.

RECIBIDO el 7 de enero de 2019 y Aprobado el 4 de junio de 2019

\section{INTRODUCCIÓN}

La contaminación ambiental es una de las problemáticas más importantes y urgentes de los últimos cincuenta años, y ha concitado a un amplio consenso entre los Estados para buscar medidas que tiendan a

* Licenciada en Ciencias Jurídicas, Pontificia Universidad Católica de Valparaíso. Doctora en Derecho por la Universidad de Barcelona. Investigadora del Instituto de Ciencias Sociales de la Universidad de O’Higgins. Av. Libertador Bernardo O’Higgins 661, Rancagua. Correo electrónico: mariapilar.navarro@uoh. cl. El presente trabajo se enmarca en el contexto del Proyecto I+D: "Tecnología y Fiscalidad en el siglo XXI” del Grupo de Investigación de Dret Tributari i Política Fiscal de la Universidad de Barcelona. 
combatirla. El origen de esta situación se encuentra en el progreso que ha experimentado la sociedad de la mano del desarrollo de la industria y la tecnología, que evidentemente han mejorado la calidad de vida de la población, pero en contraposición han generado una externalidad negativa, como es la contaminación.

El Derecho no se ha quedado indiferente a esta problemática y la respuesta ha venido a través del Derecho del medio ambiente "cuyo objetivo principal es evitar o reducir el negativo impacto del desarrollo industrial y tecnológico sobre el medio ambiente" ", y que se presenta como un factor de moderación, limitación o exclusión de desarrollo. Si bien no busca una paralización del desarrollo, sí apunta a que este sea compatible con la preservación del medio ambiente ${ }^{2}$.

La fisonomía del Derecho del medio ambiente está marcada por su interdisciplinariedad. Es así como confluyen el Derecho constitucional, que establece la necesidad de proteger el medio ambiente; el Derecho internacional, por la dimensión supraestatal de la realidad ambiental; el Derecho penal, si el Estado establece delitos ambientales; el Derecho civil, con la reparación del daño y los conflictos ambientales en el marco de las relaciones de vecindad; el Derecho administrativo, como regulador de la actividad de la Administración en cuanto esta controla la actuación de los particulares a través del ejercicio de sus atribuciones, y el Derecho tributario, que interviene cuando se regulan de tributos ambientales ${ }^{3}$.

Los tributos denominados ambientales responden a la lógica de Pigou, para quien era necesario que quienes producían y, consecuentemente, generaban contaminación, internalizasen el costo de esta externalidad negativa ${ }^{4}$. El Derecho tributario cada vez cuenta con mayor protagonismo, debido a que permite abordar el problema de la contaminación ambiental desde dos perspectivas distintas: por una parte, desincentiva la realización

${ }^{1}$ Esteve Pardo, José, Derecho del medio ambiente (3a edición, Madrid, Marcial Pons, 2014), pp. 13-14.

${ }^{2}$ Esteve, cit. (n. 1), p. 14.

${ }^{3}$ Véase Esteve, cit. (n. 1), pp. 18-19.

${ }^{4}$ Yábar Sterling, Ana, La temática ambiental en las doctrinas económicas del siglo $X X$. Introducción y aspectos generales, en ElLA Misma (dir.), La protección del medio ambiente. Aspectos económicos y jurídicos (Madrid, Marcial Pons, 2002), pp. 4546. Como afirma Mateluna Pérez, Rodrigo, Derecho tributario y medio ambiente. La posibilidad constitucional de establecer tributos ambientales en Chile (Santiago, LexisNexis, 2005), pp. 11 y 43, las externalidades negativas son una de las causas por las cuales el mercado falla en su rol de asignar eficientemente los recursos y, desde un principio, se percibió que la solución implicaba internalizar los costos ambientales. Para ello, era necesario incorporar en el ordenamiento jurídico instrumentos económicos que permitiesen imputar esos costos a los contaminadores. 
de ciertas conductas, estableciendo tributos ambientales y, por otra, permite motivar actividades o conductas opuestas, incorporando beneficios ambientales y subsidios 5 .

Hasta antes de la modificación operada por la Ley Nº 20.780, en Chile no existía un tributo con un marcado fin extrafiscal ${ }^{6}$, pese a que ciertos tributos y disposiciones impositivas particulares tenían un efecto medioambiental. Ahora bien, la citada ley establece dos tributos ambientales que gravan las emisiones al aire de ciertos contaminantes emitidos por fuentes móviles y fijas, regulados en sus artículos 3 y 8 , respectivamente. Este cambio normativo constituye una gran novedad, pues estos tributos se transforman en instrumentos de carácter económico de protección ambiental, los que si bien no prohíben la utilización de un combustible ni la emisión de contaminantes al aire, desincentivan la conducta al establecer un gravamen ${ }^{7}$.

El presente trabajo centra el análisis en el tributo que grava las emisiones de contaminantes al aire que tienen su origen en fuentes fijas y busca determinar tanto su correspondencia con el sistema tributario chileno cuanto los problemas que puede presentar. Para tales efectos, el examen se dividirá en tres partes. En la primera, se realizará un estudio dogmático del tributo y se revisarán las críticas formuladas. En la segunda, se analizarán las implicancias constitucionales que en Chile presenta el régimen jurídico de este tributo. En la tercera, se plantearán los problemas de aplicación que presenta el impuesto.

${ }^{5}$ SALASSA BoIX, Rodolfo, La protección ambiental a través de los tributos en el marco de la relación entre el deber de contribuir y el deber de preservar el medio ambiente, en Quincena Fiscal 12 (2018), p. 12, BIB 2018\9903. Es más, se ha señalado por la doctrina nacional que el tributo constituye actualmente uno de los instrumentos de regulación más eficientes para obtener modificaciones en los patrones de conducta de las personas. Matus Fuentes, Marcelo, Particularismos e imposibilidades de los impuestos a las emisiones en la Constitución Politica de Chile. Estudio preliminar, en Revista Chilena de Derecho 42 (2015), 3, p. 1042.

${ }^{6}$ Pese a la ausencia previa de tributos ambientales, la herramienta fiscal que se contemplaba en la letra c) del artículo 47 de la Ley sobre Bases Generales del Medio Ambiente, como uno de los instrumentos de los cuales se podía valer un plan de prevención o de descontaminación. Sin embargo, teniendo presente la forma como se encuentra regulada la potestad tributaria en la Constitución chilena, el impuesto solo puede ser establecido a través de una ley iniciada por mensaje presidencial.

${ }^{7}$ Véase Bermúdez Soto, Jorge, Fundamentos de Derecho ambiental (2a edición, Valparaíso, Ediciones Universitarias de Valparaíso, 2014), p. 191. 


\section{ESTRUCTURA DOGMÁTICA DEL IMPUESTO DEL ARTíCULO $8^{\circ}$}

DE LA LEY N² 20.780

\section{Antecedentes}

Como se indicó, Chile no contó con impuestos verdes hasta la dictación de la Ley $\mathrm{N}^{\circ} 20.780^{8}$, aspecto que fue apuntado por la Evaluación del Desempeño Ambiental de Chile del año 2005, efectuada por la CEPAL y de la OCDE. El informe señaló como aspecto negativo el hecho de que la política tributaria chilena no utilizase expresamente tributos con fines explícitamente ambientales y que los impuestos relacionados con el medio ambiente existentes se diseñasen prestando poca atención a sus efectos ambientales?. En tal escenario, concluyó que era necesario fomentar la integración de las consideraciones ambientales en las decisiones económicas y sectoriales, así como en los instrumentos y en la política fiscal, para mejorar el desempeño ambiental y avanzar hacia un desarrollo sustentable, profundizando en los principios quien contamina paga y el usuario paga ${ }^{10}$.

Como respuesta a la recomendación de la OCDE, en el año 2014 el Gobierno aborda la problemática ambiental desde la perspectiva impositiva, con el envío al Congreso del proyecto de la Ley $\mathrm{N}^{\circ} 20.780$, que expresamente menciona la necesidad de aumentar los impuestos ligados al cuidado del medio ambiente para incrementar la recaudación, con miras a la reforma educacional, tomando como base el modelo de la estructura tributaria de los países de mayor desarrollo ${ }^{11}$. El mensaje reconoce que la carga tributaria en Chile es baja en términos de impuestos ligados al cuidado del medio ambiente en comparación con los países de la OCDE, y señala la necesidad de establecer un impuesto a la emisión de contaminantes en la industria, ya que el uso de combustibles fósiles genera efectos negativos sobre el medio ambiente y la salud de las personas. En tal escenario, la imposición de un gravamen opera como una forma de estimular el cambio hacia tecnologías limpias ${ }^{12}$. El mensaje agrega que el impuesto sobre

${ }^{8}$ Pese a ello, el proyecto de ley que "perfecciona la legislación tributaria y financia la reforma educacional”, Boletín $N^{\circ} 8269-05$, de 3 de mayo de $2012-$ retirado el 2 de agosto del mismo año-, expresamente establecía, en su artículo 6, un impuesto verde, de carácter específico, a ciertos productos (de neumáticos, aceites y lubricantes, baterías, pilas, ampolletas y ciertos envases), atendido a que su manejo como residuos, después de terminada su vida útil, tiene un costo social importante.

${ }^{9}$ CEPAL - OCDE, Evaluaciones del desempeño ambiental. Chile 2005 (Santiago, CEPAL, 2005), p. 25.

${ }^{10}$ CEPAL - OCDE, cit. (n. 9), pp. 124, 126 y 135.

${ }^{11}$ Historia de la Ley $\mathrm{N}^{\circ}$ 20.780, disponible [en línea]: http://www.bcn.cl/ historiadelaley/nc/historia-de-la-ley/4406/, p. 5.

${ }^{12}$ Historia de la Ley $N^{\circ} 20.780$, cit. (n. 11), p. 15. Pese a la importancia de este 
las emisiones de fuentes fijas considera dos externalidades negativas: el daño a la salud, por las emisiones de Material Particulado (MP), Óxido de Nitrógeno $\left(\mathrm{NO}_{\mathrm{x}}\right)$ y Dióxido de Azufre $\left(\mathrm{SO}_{2}\right)$, y el daño global por el cambio climático, causado por las emisiones de $\mathrm{CO}_{2}{ }^{13}$.

En el año 2016 la CEPAL y la OCDE constatan los avances producidos desde el informe emitido año 2005 e indican que Chile se hizo cargo de las críticas al incorporar un impuesto sobre las emisiones de carbono, innovación es que muy bienvenida y que constituye el primer paso para aplicar el principio quien contamina paga ${ }^{14}$. Sin embargo, el principal mensaje de la nueva evaluación es que "aún no se han materializado plenamente los efectos beneficiosos para el medio ambiente"15, por lo que "durante la próxima década se deberá llevar adelante una reforma profunda" ${ }^{16}$.

\section{Estructura dogmática}

El impuesto establecido en el artículo 8 de la Ley $N^{\circ} 20.780$ entró a regir el $1^{\circ}$ de enero de 2017, según lo dispuesto en el artículo decimocuarto transitorio de la referida ley, y fue pagado por primera vez en el año tributario $2018^{17}$. Es de aquellos gravámenes ambientales sobre emisiones que con mayor intensidad intentan poner en práctica el principio de corrección en la fuente, según el cual, "la acción pública en defensa del ambiente debe tener lugar antes de que lo exija el debilitamiento ambiental, de modo que los daños ambientales se traten «en origen"” 18 .

$\mathrm{Al}$ respecto, se debe señalar que el inciso 13 del artículo 8 de la ley dis-

cambio, la protección del medio ambiente no se incluye dentro de los objetivos de la reforma, lo que para Faúndez podría tener dos explicaciones: considerar que la omisión es un error del legislador, o bien, concluir que estos tributos no tienen una finalidad ambiental, sino derechamente recaudatoria. FAÚndEZ UGALDE, Antonio DalRi TIMm do Valle, Mauricio, Hacia una nueva normativa tributaria de protección del medio ambiente: la experiencia comparada en el Derecho tributario brasileño, en Revista de Estudios Tributarios 10 (2014), pp. 106-107.

${ }^{13}$ El objetivo de este impuesto es lograr una disminución de gases de efecto invernadero (GEI). CoRONADO LAGOS, Evelyn, Impuesto chileno sobre emisiones a la atmósfera provenientes de fuentes fijas. (Un estudio a la luz de la legislación española) (Madrid, Instituto de Estudios Fiscales, 2016), p. 12, documento $\mathrm{N}^{\circ} 2$.

${ }^{14}$ CEPAL - OCDE, Evaluaciones del desempeño ambiental. Chile 2016 (Santiago, CEPAL, 2016), pp. 32 y 205.

${ }^{15}$ CEPAL - OCDE, cit. (n. 14), p. 3.

${ }^{16}$ CEPAL - OCDE, cit. (n. 14), p. 3.

${ }^{17}$ En adelante, cuando se haga mención a la ley, se hará referencia a la Ley $\mathrm{N}^{\circ}$ 20.780 .

${ }^{18}$ García Novoa, César, El Reglamento del impuesto gallego sobre Contaminación Atmosférica. Puntualizaciones a la Sentencia del TSJ de Galicia de 3 de julio de 2001, en Repertorio de Jurisprudencia 33 (2002), pp. 2-3, BIB 2002\1971. 
pone que el Ministerio del Medio Ambiente deberá dictar un reglamento en el que fije las obligaciones y procedimientos relativos a la identificación de los contribuyentes afectos y establecerá los procedimientos administrativos necesarios para la aplicación del impuesto. En cumplimiento de este mandato legal, el citado Ministerio dictó el Reglamento $\mathrm{N}^{\circ} 18$, del año 2016, al que en lo sucesivo se hará referencia como el Reglamento ${ }^{19}$.

Centrando el análisis en los aspectos dogmáticos del tributo, el artículo 8 de la ley establece como hecho gravado la emisión de ciertos contaminantes emitidos por determinadas fuentes fijas; en concreto, los contaminantes cuya emisión al aire resulta gravada son: Material Particulado (MP), Óxido de Nitrógeno $\left(\mathrm{NO}_{\mathrm{x}}\right)$, Dióxido de Azufre $\left(\mathrm{SO}_{2}\right)$ y Dióxido de Carbono $\left(\mathrm{CO}_{2}\right)$.

Ahora bien, no es suficiente con que haya emisión al aire de estos contaminantes para que se verifique el hecho gravado, sino que además se exige que la emisión tenga su origen en dos fuentes fijas concretas: calderas ${ }^{20}$ o turbinas ${ }^{21}$, que individualmente consideradas o en su conjunto sumen una potencia térmica igual o superior a $50 \mathrm{MWt}$ (megavatios térmicos), considerando el límite superior del valor energético del combustible ${ }^{22-23}$.

La forma como está regulado el impuesto determina que lo relevante para los efectos del gravamen sea tanto la calificación que tenga una determinada fuente fija como la potencia térmica global. Por este motivo el Reglamento del Ministerio del Medio Ambiente ha establecido una obligación de registrarse en el Registro de Calderas y Turbinas para toda persona natural o jurídica propietaria de una o más calderas y/o turbinas

\footnotetext{
${ }^{19} \mathrm{Al}$ marco jurídico indicado, deben agregarse las interpretaciones efectuadas por el Servicio de Impuestos Interno en las Circulares Nos 52, de 2015 y 47, de 2016. La Resolución Exenta $N^{\circ} 55$, de 2018, de la Superintendencia del Medio Ambiente y la Resoluciones Exentas Nos 659, de 2017 y 52, 2018 de la Comisión Nacional de Energía.

${ }^{20}$ De conformidad con el artículo 2 letra e) del Reglamento se entiende por caldera, la unidad principalmente diseñada para calentar agua o un fluido térmico y/o para generar vapor de agua, mediante la acción del calor.

${ }^{21}$ De conformidad con el artículo 2 letra f) del Reglamento, se entiende por turbina la máquina rotativa que capta la energía de un fluido transformándola en energía mecánica rotacional, utilizando la expansión del fluido por efecto de la quema de un combustible, sea este líquido o gaseoso, en una cámara de combustión interna, generando con ello trabajo útil.

22 De conformidad con lo dispuesto en el inciso 11 del artículo 8 de la ley, el Ministerio del Medio Ambiente publicará anualmente un listado de los establecimientos que se encuentran en esta situación.

${ }^{23}$ El mensaje del proyecto de la Ley $\mathrm{N}^{\circ} 20.780$ señala que debido al tamaño de las fuentes fijas contempladas en el artículo 8 no afectaría a las pequeñas y medianas empresas. Historia de la Ley $\mathrm{N}^{\circ} 20.780$, cit. (n. 11), p. 15.
} 
con una potencia térmica norma superior a $5 \mathrm{MWt}$. Junto con el registro se deberá acompañar cierta información; el objetivo perseguido es obtener a partir de estos antecedentes el listado anual de establecimientos afectos ${ }^{24}$, el que, sin embargo, tiene un carácter meramente informativo, pues el inciso 2 del artículo 9 del Reglamento dispone que la omisión de algún establecimiento en la publicación "no significará necesariamente que estos no se encuentren o no puedan encontrarse en el futuro en la hipótesis establecida en el inciso primero del artículo 8 de la Ley $N^{\circ} 20.780$ ".

Por otra parte, el sujeto pasivo del impuesto es aquella persona, natural o jurídica que, haciendo uso las fuentes de emisión de los establecimientos afectos, genere emisiones de los compuestos contaminantes gravados, independientemente de quién es el dueño y a qué título se hace uso de estos establecimientos ${ }^{25}$.

En relación con este punto el Servicio de Impuestos Internos, en adelante SII, ha señalado expresamente en el Oficio $\mathrm{N}^{\circ} 1605$, de 2 de agosto de 2018 que "no cabe dudas que compete privativamente al Ministerio del Medio Ambiente - para efectos de determinar el listado anual de establecimientos afectos y llevar el registro de fuentes emisoras contaminantes (turbinas y calderas) - determinar quién es el sujeto pasivo (contribuyente) del denominado impuesto a las fuentes fijas contaminantes, así como las 'calderas y turbinas' que deben considerarse como conformando un 'establecimiento afecto', sin que corresponda a este Servicio participación legal o técnica alguna en dicho procedimiento, salvo proceder al cálculo del impuesto por emisión de $\mathrm{MP}, \mathrm{CO}_{2}, \mathrm{NO}_{\mathrm{X}}$ y $\mathrm{SO}_{2}$, por cada contribuyente, conforme la información que, al efecto, le remita la Superintendencia del Medio Ambiente". La Administración tributaria expresamente señala no ser competente para identificar al contribuyente del impuesto, y pareciera limitar su intervención al mero cálculo del impuesto en base a la información suministrada por otras reparticiones públicas. Con todo, si el giro del impuesto es reclamado, será el SII el que deberá litigar ante los Tribunales Tributarios y Aduaneros ${ }^{26}$.

${ }^{24}$ Artículos 3 a 10 del Reglamento.

${ }^{25}$ En España, Rozas da cuenta de que en la formulación del hecho imponible se procura prescindir la titularidad patrimonial, para no colisionar con la materia imponible del Impuesto sobre Bienes Inmuebles (IBI) y no sufrir una declaración de inconstitucionalidad por este hecho. Rozas Valdés, José Andrés, Riesgo de contaminar y tributos autonómicos, en Quincena Fiscal 2 (2006), p. 2, BIB 2006\18.

${ }^{26}$ Debe tenerse presente que el proyecto de modernización de la legislación tributaria presenta un cambio en lo que se refiere al tribunal competente para conocer del reclamo del giro, ya que se incluiría la posibilidad de reclamar ante el Tribunal Ambiental. En efecto, el artículo $16 \mathrm{~N}^{\circ} 8$ expresa que: "del giro podrá reclamarse ante 
El impuesto no contempla un mínimo exento, con lo cual, independientemente de la cantidad de toneladas emitidas al aire, si se emite por un establecimiento afecto, se realizará el hecho imponible y surgirá la obligación tributaria. Ahora bien, evidentemente para cuantificar la obligación tributaria es necesario que conste que tuvo lugar una emisión de contaminantes al aire por las fuentes fijas antes señaladas, para lo cual deberán ser medidas y registradas ${ }^{27}$.

En este punto, cabe destacar que la legislación chilena encomendó a la Superintendencia del Medio Ambiente, en adelante SMA, determinar la forma en que la medición de las emisiones tendría lugar y fiscalizar el cumplimiento de estas obligaciones de monitoreo, registro y reporte ${ }^{28}$. El incumplimiento de estas obligaciones será sancionado por la SMA, de conformidad con lo establecido en el inciso 16 del artículo 8 de la ley.

La SMA, en cumplimiento de su obligación legal, determinó la forma como se debe efectuar la medición, siendo el instructivo actualmente vigente la Res. Ex. SMA N ${ }^{\circ} 55$, de 12 de enero de 2018, que contempla distintas metodologías que se pueden utilizar; lo común a todas ellas es que la medición la efectúa el contribuyente, quien posteriormente remite los datos a la autoridad ambiental ${ }^{29}$.

el Tribunal Ambiental correspondiente al domicilio de la fuente emisora, conforme las reglas generales".

27 Véase Mateluna, cit. (n. 4), p. 34, para quien es imprescindible que se acrediten las emisiones del contribuyente para que se le pueda gravar. Solo así se respetan las exigencias del principio quien contamina paga, el que cumple, a su juicio, un doble rol, pues no solo se encuentra a la base del establecimiento de los impuestos ambientales, sino que a la vez constituye su límite.

${ }^{28}$ En efecto, el inciso 14 del artículo 8 de la ley prescribe que: "las características del sistema de monitoreo de las emisiones y los requisitos para su certificación serán aquellos determinados por la Superintendencia del Medio Ambiente para cada norma de emisión para fuentes fijas que sea aplicable. La certificación del sistema de monitoreo de emisiones será tramitada por la precitada Superintendencia, quien la otorgará por resolución exenta. Para estos efectos, la Superintendencia del Medio Ambiente fiscalizará el cumplimiento de las obligaciones de monitoreo, registro y reporte que se establecen en el presente artículo".

${ }^{29}$ En concreto este aspecto se encuentra regulado en el Título I, denominado "Instructivo para la cuantificación de las emisiones de fuentes fijas afectas al impuesto del artículo 8 de la Ley $\mathrm{N}^{\circ}$ 20.780". La instrucción establece que la cuantificación puede tener lugar mediante un muestreo o medición -sea a través de medición con métodos de referencia o continua-, o bien a través de estimación. Ello da lugar a siete alternativas de medición regladas, pero se acepta, si ninguna de las alternativas propuestas pueda ser aplicada por un establecimiento afecto debido a una imposibilidad técnica debidamente justificada, que el contribuyente pueda proponer una metodología de cuantificación que sea reconocida internacionalmente. 
El impuesto presenta una base imponible de carácter no monetario ${ }^{30}$, ya que corresponde a la cuantía de la carga contaminante de las emisiones gravadas que se emitan desde las fuentes fijas señaladas durante el período impositivo, medidas en toneladas ${ }^{31}$.

En cuanto a la tasa el impuesto, hay que señalar que variará según el contaminante de que se trate:

a) En el caso de los contaminantes diversos al $\mathrm{CO}_{2}$, el inciso 3 del artículo 8 dispone que el impuesto será el equivalente a 0,1 por cada tonelada emitida, o la proporción que corresponda de dichos contaminante, cantidad que se multiplica por el costo social de contaminación per capita

A este respecto, la CEPAL y la OCDE han apuntado que el monitoreo continuo de las emisiones puede resultar relativamente costoso, por lo que sugieren hallar el punto de equilibrio para determinar el grado de cobertura que resulta sensato lograr. CEPAL - OCDE, cit. (n. 14), p. 148.

Cabe señalar que el Oficio SII No 3104, de 18 de noviembre 2016 ha entendido que la adquisición de sistemas tanto de medición continua de las emisiones (CEMS) -que son instalados en las turbinas y/o calderas con el objetivo de medir con mayor precisión las emisiones efectuadas-, como de abatimiento -que son instalados en las calderas y/o turbinas, los que sirven para disminuir sus emisiones al aire de estos contaminantes-, en tanto hayan sido adquiridos con el ánimo o intención de usarlos en la explotación, sin el propósito de revenderlos o ponerlos en circulación y en el entendido que se trata de bienes físicos, se encuentran comprendidos dentro del concepto de activo inmovilizado. La instrucción estima que, de ser procedente según las reglas generales, corresponde aplicar respecto de tales bienes, la corrección monetaria del artículo $42 \mathrm{~N}^{\circ} 1$ de la Ley sobre Impuesto a la Renta y la depreciación. Agrega que pese a que en cada fiscalización debe verificarse el cumplimiento de los requisitos legales, "en todos aquellos casos en que una norma legal o administrativa establece la obligación de la empresa de instalar dichos componentes, se cumple con los requisitos ya que la empresa está obligada a ejercer su actividad cumpliendo las normas legales que la rigen. Por otra parte, respecto de las empresas que, no estando obligadas a efectuar dicha adquisición, igualmente decidan instalar un sistema de medición de emisiones o de disminución de emisiones, podrán efectuar depreciación de estos siempre que acrediten que el uso de dichos sistemas es necesario para el mejor funcionamiento de la empresa, y en consecuencia, para producir la renta de ésta". Y, en principio, el Oficio afirma que debe entenderse que "todo desembolso dirigido a evitar, neutralizar o reparar externalidades negativas provocadas al medio ambiente, constituye un gasto necesario para producir la renta, ya que los contribuyentes se encuentran obligados a desarrollar sus actividades, respetando no sólo el texto expreso de la legislación medioambiental, sino que además, los objetivos generales de dicha legislación".

${ }^{30}$ Coronado, cit. (n. 13), p. 22.

31 Contreras Rojas, María José - Pinochet Abalos, María Jesús, Análisis comparado del impuesto chileno a las emisiones de contaminantes provenientes de fuentes fijas a la luz de la normativa española, en Crónica Tributaria 165 (2017), p. 17. 
del contaminante y por la población de la comuna ${ }^{32}$; dándose ciertos requisitos, se multiplica también por un coeficiente de calidad del aire.

En efecto, si el establecimiento no se encuentra ubicado en comunas declaradas zona latente o saturada, la tasa considera solo el costo social per capita de la contaminación del contaminante por el total de la población de cada comuna. En cambio, si el establecimiento se encuentra ubicado en comunas declaradas zona latente ${ }^{33} \mathrm{o}$ saturada ${ }^{34}$, adicionalmente habrá que aplicar un coeficiente de calidad del aire ${ }^{35}$, el que será de 1,2 respecto de las zonas saturadas y de 1,1 en las zonas latentes ${ }^{36}$.

Según establece el inciso 11 del artículo 8 de la ley, el Ministerio del Medio Ambiente deberá publicar anualmente el listado de las comunas que han sido declaradas como saturadas o latentes para los efectos de este impuesto, el que de conformidad con el inciso 2 del artículo 15 del Reglamento será enviado a la SMA a más tardar el 30 de enero de cada año ${ }^{37}$. El artículo 14 del Reglamento precisa que toda la comuna será considerada como zona latente o saturada, cuando esta calidad la tenga a

${ }^{32}$ La fórmula de cálculo indicada en la ley es la siguiente: Tij = CSCpci X Pobj, donde "Tij", es la tasa del impuesto por tonelada del contaminante, "i” es el emitido en la comuna "j" medido en US\$; "CSCpci" es el costo social de contaminación per capita del contaminante "i” y "Pobj", es la población de la comuna “j”. De conformidad con lo dispuesto en el inciso 8 del artículo 8 de la ley, la población de la comuna se determinará para cada año de acuerdo con la proyección oficial del Instituto Nacional de Estadísticas. En dólares, la cuantificación de cada contaminante es la siguiente, según dispone el inciso 5 del artículo 8 de la ley: Material Particulado, US \$ 0.9; Dióxido de Azufre, US \$0.01, y Óxido de Nitrógeno US\$0.025.

33 Según el artículo 2, letra t) de la Ley sobre Bases Generales del Medio Ambiente, una zona latente es aquella "en que la medición de la concentración de contaminantes en el aire, agua o suelo se sitúa entre el $80 \%$ y el $100 \%$ del valor de la respectiva norma de calidad ambiental". Las normas de calidad establecen los valores de las concentraciones y períodos máximos o mínimos permisibles de, en general, elementos, cuya presencia o carencia en el ambiente pueda constituir un riesgo para la vida o salud de la población, en el caso de las normas primarias de calidad, o para la conservación del medio ambiente o la preservación de la naturaleza, respecto de las normas secundarias de calidad, según disponen las letras n) y ñ) de la Ley sobre Bases Generales del Medio Ambiente.

${ }^{34}$ Según el artículo 2, letra u) de la Ley sobre Bases Generales del Medio Ambiente es aquella: "en que una o más normas de calidad ambiental se encuentran sobrepasadas".

${ }^{35} \mathrm{~L}$ a fórmula de cálculo indicada en la ley es la siguiente: Tij=CCAj×CSCpci×Pobj, donde "CCAj", es el coeficiente de calidad del aire en la comuna "j".

${ }^{36}$ El proyecto de ley de modernización tributaria precisa, en el artículo $16 \mathrm{~N}^{\circ}$ 3 que la declaración de zona latente o saturada debe ser por concentración del respectivo contaminante gravado.

${ }^{37}$ Actualmente se encuentra vigente la Res. Ex. $N^{\circ} 1416$, del Ministerio del Medio Ambiente, de 21 de diciembre de 2018, que contiene un listado de 92 
una parte o fracción de la comuna respectiva; asimismo, si una comuna es parte de distintas zonas (saturas o latentes) primará el coeficiente aplicable a la zona saturada.

b) En el caso del $\mathrm{CO}_{2}$, hay una estandarización, ya que se establece que el impuesto será de 5 dólares por cada tonelada emitida ${ }^{38}$. Pese a que, como se señalara, la legislación no contempla un mínimo de emisión exento, respecto a las emisiones de $\mathrm{CO}_{2}$ consagra una exención en el inciso 9 del artículo 8 de la ley. La disposición establece que el impuesto no se aplicará para fuentes fijas que operen en base a medios de generación renovable no convencional cuya fuente de energía primaria sea la energía biomasa ${ }^{39}$.

En la citada Resolución Exenta SMA N 55, la autoridad ambiental instruyó la forma de reportar y verificar las emisiones. En lo que se refiere a la verificación de la información reportada, la SMA ha manifestado que ello comprende la metodología de cuantificación, las condiciones de medición, muestreo y/o estimación, y de la información reportada ${ }^{40}$. De otra parte, en relación con la obligación de reportar, se señala que ella tiene lugar a través de la ventanilla única del Registro de emisiones y transferencia de contaminantes; sin embargo, dependiendo del tipo de fuente las emisiones se efectuarán en el sistema de termoeléctricas ${ }^{41}$, o bien en el

establecimientos afectos, la que además determina las comunas que se encuentran declaradas como zona latente o saturada.

${ }^{38}$ Se ha señalado que el valor se habría fijado teniendo presente el estudio "Estimación Precio Social del Carbono" del año 2013, realizado por la División de Evaluación Social de Inversiones del Ministerio de Desarrollo Social, el que señala dos metodologías para estimar el costo social del carbono: en base al cálculo de daños o en base a la disposición al pago. Sin embargo, dadas las dificultades para estimar este precio, se ha propuesto utilizar el precio de mercado como costo social. Coronado, cit. (n. 13), p. 20.

${ }^{39}$ El texto original del proyecto de ley no contempló esta exención, sino que se incorporó luego de suscrito el Protocolo de Acuerdo por una reforma tributaria para un Chile más Inclusivo, el que en el punto 9 señaló que "se excluirá del referido impuesto a aquellas fuentes que utilicen biomasa como combustible". Durante la tramitación parlamentaria, la Corporación Chilena de la Madera manifestó por escrito que la reforma tributaria debería diferenciar la naturaleza del combustible utilizado en las calderas, por cuanto la industria de la madera usaba biomasa para tales efectos, a través de un mecanismo sustentable y controlado ambientalmente. Historia de la Ley $\mathrm{N}^{\circ} 20.780$, cit. (n. 11) p. 763. El proyecto de ley de modernización de la legislación tributaria precisa en su artículo $16 \mathrm{~N}^{\circ} 5$ que la utilización de aditivos en la combustión de biomasa no altera la liberación.

${ }^{40}$ Título 3, "Instructivo para la verificación de las emisiones de fuentes fijas afectas al impuesto del artículo 8 de la Ley $\mathrm{N}^{\circ} 20.780$ ”, de la Resolución Exenta SMA N 55, de 2018.

${ }^{41}$ Véase el Título III del Decreto Supremo $N^{\circ} 13$, del Ministerio del Medio 
sistema de impuesto verde y deberá entregarse la información en cuatro períodos en el año ${ }^{42}$.

En concreto, la información que la SMA debe remitir está especificada en el inciso 1 del artículo 16 del Reglamento, y consiste en:

“a) Rol único tributario;

b) Identificación del establecimiento afecto y la potencia (en megavatios térmicos) de las fuentes que forman parte del establecimiento;

c) Toneladas emitidas de material particulado;

d) Toneladas emitidas de óxido de nitrógeno;

e) Toneladas emitidas de dióxido de azufre;

f) Número y fecha de la consolidación de las emisiones;

g) Comuna y coeficiente de calidad del aire aplicable;

h) Toneladas de dioxido de carbono emitidas no consideradas en fuentes de operación en base a medios de generación renovable no convencional cuya fuente de energía primaria sea biomasa contemplada en el numeral 1), de la letra aa) del artículo 225 del DFL $N^{\circ}$ 4, de 2006, del Ministerio de Economía, Fomento y Reconstrucción;

i) Identificación de la o las fuentes emisoras respectivas;

j) Población de la comuna respectiva proyectada oficialmente por el Instituto Nacional de Estadisticas para el año respectivo".

Los casos de empleo de medios de generación convencional no renovable cuya fuente de energía primaria es la biomasa constituye un supuesto de exención. Por ello se explica que pese a que se encuentre exento, de todos modos el contribuyente debe reportar tales emisiones, lo que desde un punto de vista de política ambiental puede resultar relevante para tener una idea de la cantidad total de toneladas emitidas.

El impuesto se devenga anualmente, y según lo prescrito en el inciso 10 del artículo 8 de la ley debe pagarse en la Tesorería General de la República en el mes de abril del año calendario siguiente a la generación de emisiones, previo giro efectuado por el SII, y dispone que el retardo en enterar el impuesto determinado en la Tesorería se sancionará según lo dispuesto en el artículo $97 \mathrm{~N}^{\circ} 11$ del Código Tributario.

Cabe apuntar que un aspecto interesante de este impuesto, y que como se verá genera un importante problema aplicativo, es el hecho de que el

Ambiente, de 2011, que establece norma de emisión para centrales termoeléctricas.

42 Según establece el punto 7 del Título 2 "Instructivo para el reporte de las emisiones de fuentes fijas afectas al impuesto del artículo 8 de la Ley $\mathrm{N}^{\circ} 20.780$ ", de la Resolución Exenta SMA No 55, de 2018, se debe reportar: a) período de enero, febrero y marzo, el 30 de abril; b) período de abril, mayo y junio, el 31 de julio; c) período de julio, agosto y septiembre, el 31 de octubre, y d) período de octubre, noviembre y diciembre, el 31 de enero del año siguiente. 
SII emite el giro en base a la información de las emisiones que le remite la SMA, la que en el mes de marzo consolida la información sobre las emisiones informada por el contribuyente el año calendario anterior ${ }^{43}$. El giro se emitirá en dólares de Estados Unidos de América y será notificado según las reglas generales ${ }^{44}$, pero su pago se efectuará en moneda nacional, de acuerdo con el tipo de cambio observado vigente a la fecha de pago ${ }^{45}$. De ello se desprende que el impuesto es de aquellos denominados de giro, ya que el mismo no es declarado por el contribuyente; la estructura del impuesto presupone que la determinación de la obligación tributaria es efectuada por el SII.

Finalmente, es necesario apuntar que este impuesto no deberá ser considerado en la determinación del costo marginal instantáneo de energía, cuando este afecte a la unidad de generación marginal del sistema, según dispone el inciso final del artículo $8^{46}$.

\section{Críticas a la regulación del impuesto sobre las emisiones al aire de} fuentes fijas

Es innegable que la incorporación de este impuesto constituye un avance en orden a proteger el medio ambiente, aspecto que por lo demás, también destacan la CEPAL y la OCDE. Sin embargo, existen críticas

${ }^{43}$ Ello, de conformidad con el inciso 12 del artículo 8 de la ley, reiterado por el artículo 13 del Reglamento.

${ }^{44}$ Artículo 18 del Reglamento.

45 Artículo 19 del Reglamento. El impuesto pagado, para los efectos de la Ley sobre Impuesto a la Renta puede ser deducido como gasto tributario por los contribuyentes de primera categoría en la determinación de la renta líquida imponible, según dispone el artículo $31 \mathrm{~N}^{\circ} 2$ de dicha ley, criterio que ha sido ratificado por el Oficio SII No 3104, de 18 de noviembre de 2016, el que señala que corresponde a un impuesto que "se relaciona con el giro de la empresa y no ha sido sustituido por una inversión en beneficio del contribuyente".

${ }^{46} \mathrm{La}$ norma, sin embargo, prescribe que para las unidades cuyo costo total unitario, siendo este el costo variable considerado en el despacho, adicionado el valor unitario del impuesto, sea mayor o igual al costo marginal, la diferencia entre la valorización de sus inyecciones a costo marginal y a dicho costo total unitario, deberá ser pagado por todas las empresas eléctricas que efectúen retiros de energía del sistema, a prorrata de sus retiros, debiendo el Centro de Despacho Económico de Carga respectivo, adoptar todas las medidas pertinentes para realizar la reliquidación correspondiente. Por su parte, el inciso final del artículo 12 del Reglamento dispone que, en estos casos, el reporte que debe remitirse a la Superintendencia del Medio Ambiente asociado a las emisiones de aquellas unidades de generación sujetas a coordinación del Centro de Despacho Económico de Carga deberá contener una desagregación a nivel horario de las emisiones. 
importantes que apuntan a cuestionar si el impuesto del artículo 8 es eficaz para el objetivo perseguido, esto es, reducir la contaminación ambiental.

$\mathrm{Al}$ respecto, se ha criticado la regulación del hecho gravado mismo, ya que se señala que es bastante restrictivo, al considerar solo las emisiones que tienen lugar en dos fuentes fijas, pues se limita el gravamen a las emisiones de turbinas y calderas, con lo cual se excluyen aquellas que emanan de los hornos y fundiciones de la minería, particularmente contaminantes ${ }^{47}$, sin que exista una razón medioambiental para la exclusión ${ }^{48}$. Tal vez esto explique el cambio que prevé la ley de modernización a la legislación tributaria, que elimina la precisión de las fuentes fijas concretas cuyas emisiones se encuentran gravadas ${ }^{49}$.

De otra parte, se ha manifestado la conveniencia de establecer un sustituto tributario, para evitar dificultades en la determinación del sujeto pasivo en aquellos supuestos en que el contribuyente (quien hace uso de la instalación), no sea el dueño ${ }^{50}$. Sin embargo, no se estima que exista dificultad para determinar el sujeto pasivo, habida cuenta de las exigencias contenidas en el Reglamento a propósito del Registro de Calderas y Turbinas.

Asimismo se ha criticado lo acotado de los contaminantes gravados, por lo que se ha propuesto ampliar la lista en el futuro ${ }^{51}$. Se señala tam-

47 La evaluación de la CEPAL y de la OCDE del 2005 advirtió que las emisiones de $\mathrm{SO}_{x}$, pese a que habían experimentado una reducción, eran muy altas, principalmente, debido a las fundiciones de cobre. CEPAL - OCDE, cit (n. 9), pp. 19, 26, 37, 43 y 60. Tal escenario explica que estos organismos al analizar nuevamente la situación de Chile en materia ambiental en el año 2016 señalaran que resulta criticable que el tributo grave principalmente las centrales termoeléctricas, pero deje de lado otras grandes fuentes de emisiones, como las fundiciones de cobre, que son responsables de gran parte de la contaminación atmosférica, por lo que recomendaron incluirlas. CEPAL - OCDE, cit. (n. 14) pp. 18, 32, 38 y 147-148.

${ }^{48}$ De hecho, durante la tramitación de la Ley $\mathrm{N}^{\circ} 20.780$, se manifestó en la discusión en la Sala de la Cámara de Diputados que era necesario evaluar la restricción en las fuentes fijas, ya que existían "muchas otras fuentes contaminantes, que también se deberían incluir en el sentido ambiental de esta norma”. Historia de la Ley $\mathrm{N}^{\circ} 20.780$, cit. (n. 11), p. 1135.

${ }^{49}$ Ahora bien, el texto de la reforma especifica que el gravamen solo tendrá lugar cuando las emisiones, individualmente consideradas o en su conjunto, emitan $100 \mathrm{o}$ más toneladas anuales de material particulado o 25.000 o más toneladas anuales de dióxido de carbono. Con lo cual no se encontrarían gravadas las emisiones de fuentes contaminantes que no alcancen el estándar señalado, como ocurre, por ejemplo, en el caso de algunas generadoras de respaldo. Véase el artículo $16 \mathrm{~N}^{\circ} 1$ del proyecto de modernización de la legislación tributaria.

${ }^{50}$ Coronado, cit. (n. 13), p. 22.

${ }^{51}$ Coronado, cit. (n. 13), p. 45. 
bién que la tasa impositiva aplicada sobre el $\mathrm{CO}_{2}$ es relativamente baja, por lo que sugiere que se incremente conforme a etapas preestablecidas, con el fin de reflejar en mayor medida el costo social de las emisiones ${ }^{52}$. En el mismo sentido, se ha expresado que la diferencia en el costo social de cada contaminante demuestra el poder de contaminación distinto que cada uno posee; pese a ello, se critica el hecho de que no se indique cómo se obtiene el valor ${ }^{53}$. La reforma tributaria se hace cargo parcialmente de estas consideraciones, pues prescribe que el costo social de contaminación per capita será revisado cada diez años por el Ministerio del Medio Ambiente $^{54}$. Sin embargo, esta revisión pareciera no alcanzar a la tasa del $\mathrm{CO}_{2}$, toda vez que los cinco dólares establecidos en el inciso 9 del artículo 8 no representan el costo social de la contaminación, sino tasa del impuesto, sin que existan motivos aparentes que permitan sujetar a las emisiones de $\mathrm{CO}_{2}$ a un tratamiento diverso en este punto.

En lo que respecta a la tasa del impuesto, se señala como aspecto positivo que esta tome en cuenta el costo social de los distintos contaminantes y la magnitud de la población afectada, es decir, de los habitantes de las municipalidades en las que se generan las emisiones ${ }^{55}$. No obstante lo anterior, se ha recomendado ampliar la base geográfica del componente de contaminación del aire del impuesto, más allá de solo tomar en cuenta la población del municipio, pues los contaminantes pueden extenderse a zonas relativamente extensas, por lo que considera habría sido preferible incluir en el cálculo a toda la población de la cuenca atmosférica pertinente $^{56}$. Este aspecto no ha sido recogido por la reforma tributaria.

Por último, se ha señalado que el impuesto tiene vínculos con el sistema de fijación de precios de la electricidad, y que de hecho protege a determinados generadores de energía ${ }^{57}$, a pequeñas empresas y a hogares, que

${ }^{52}$ CEPAL - OCDE, cit. (n. 14), pp. 18, 32, 38 y 147.

${ }^{53}$ Coronado, cit. (n. 13), p. 22.

${ }^{54}$ Véase el artículo $16 \mathrm{~N}^{\circ} 4$ del proyecto de modernización de la legislación tributaria. Con todo, se estima que esta regulación puede presentar problemas en relación con el principio de reserva legal, toda vez que un elemento para determinar la tasa del impuesto, como es el costo social de contaminación per capita del contaminante, el proyecto contempla que sea revisado por el Ministerio del Medio Ambiente. Si por revisar se entiende modificar el valor asignado en la ley, un elemento del tributo se estaría determinando por una norma infra legal, situación no permitida por el texto constitucional.

${ }^{55}$ CEPAL - OCDE, cit. (n. 14), pp. 32 y 148.

${ }^{56}$ CEPAL - OCDE, cit. (n. 14), pp. 38 y 148.

${ }^{57}$ Se indica que el diseño del sistema para licitar contratos de producción energética a largo plazo permitirá que algunas centrales de combustibles fósiles no tengan que pagar el importe total del tributo. CEPAL - OCDE, cit. (n. 14), p. 147. 
quedan exentos ${ }^{58}$. En este sentido, se ha propuesto evaluar las interacciones entre los mecanismos de fijación de precios de la electricidad y el impuesto sobre el $\mathrm{CO}_{2}$, y considerar los ajustes necesarios para salvaguardar que el impuesto siga siendo plenamente efectivo, ya que su propósito es aumentar los costos en que deben incurrir las centrales que generan electricidad a partir de combustibles fósiles, a fin de promover la adopción de fuentes energéticas con bajas emisiones de carbono ${ }^{59}$.

De todo lo expresado, cabe señalar que efectivamente hay aspectos normativos del tributo que deben ser mejorados por el legislador, pero es necesario tener presente que la implementación de los impuestos verdes tiene un carácter gradual, a fin de incentivar a los contribuyentes a incorporar medidas de mitigación que reduzcan sus niveles de contaminación, y una vez que se ha logrado un cambio en la conducta contaminante, de manera progresiva, profundizar y/o ampliar los ámbitos gravados ${ }^{60}$.

\section{LA EXTRAFISCALIDAD, EL PRINCIPIO QUIEN CONTAMINA PAGA Y LAS NORMAS CONSTITUCIONALES QUE REGULAN LA POTESTAD TRIBUTARIA}

\section{La extrafiscalidad tributaria y el principio quien contamina paga}

El tributo es una "obligación legal de derecho público y de carácter pecuniario, establecida a favor de un ente público, para el cumplimiento de sus fines y que recae sobre quien realiza ciertos hechos que manifiestan su capacidad económica"61. La verificación del presupuesto de hecho establecido en la ley tributaria hará nacer la obligación tributaria principal, que es una obligación ex lege, y que consiste en enterar dinero en arcas fiscales para financiar gastos públicos ${ }^{62}$. De esta forma, solo se estará ante un tributo cuando estas cantidades se adquieran por la Administración en

${ }^{58}$ La limitación en el caso de los hogares podría limitar el objetivo de un consumo más racional. CEPAL - OCDE, cit. (n. 14), p. 147.

${ }^{59}$ CEPAL - OCDE, cit. (n. 14), pp. 32, 38 y 147.

${ }^{60}$ No se debe perder de vista que el tributo comenzó a regir años después de la dictación de la Ley $\mathrm{N}^{\circ} 20.780$, con lo cual, se dio tiempo a las industrias que utilizaban calderas y turbinas a adoptar medidas que permitieran disminuir sus emisiones. Mismo camino sigue el artículo trigésimo primero transitorio del proyecto de modernización de la legislación tributaria cuando prescribe que las modificaciones al impuesto verde comenzarán a regir al publicarse la ley en el Diario Oficial, con excepción del cambio al inciso 1 del artículo 8 , que estará en vigor a partir del $1^{\circ} \mathrm{de}$ enero de 2020.

${ }^{61}$ Massone Parodi, Pedro, Principios de Derecho Tributario (4a edición, Santiago, LegalPublishing, 2016), II, p. 1060.

${ }^{62}$ Varona Alabern, Juan Enrique, Extrafiscalidady dogmática tributaria (Madrid, Marcial Pons, 2009), p. 15. 
forma definitiva y a título de dueño, es decir, que haya una sesión definitiva de riqueza y que se encuentre disponible ${ }^{63}$.

El artículo $19 \mathrm{~N}^{\circ} 20$ de la Constitución Política de la República prescribe que la Carta Fundamental asegura a todas las personas: "20 igual repartición de los tributos en proporción a las rentas o en la progresión o forma que fije la ley, y la igual repartición de las demás cargas públicas". En esta disposición no se encuentra de manera expresa la idea de que a través de los tributos se contribuye al sostenimiento de los gastos públicos, sino que se consagra el principio de igualdad en materia tributaria en lo que se refiere a la repartición de los tributos en tanto carga pública. Pese a ello, la doctrina entiende que dentro del concepto de tributo se comprenden aquellas prestaciones que las personas han de enterar en arcas fiscales cuya finalidad es cubrir el gasto público ${ }^{64}$.

De la concepción de tributo pareciera que es central la idea de recaudar dinero para que el ente público pueda cumplir su finalidad de promover el bien común. La extrafiscalidad tributaria rompe esta lógica, pues en estos casos el tributo deja de tener como foco la recaudación. Esto queda claro si se examina la definición de los tributos extrafiscales, pues se señala que "son aquellos que en su fundamento y estructura son concebidos para lograr una finalidad de carácter no fiscal" ${ }^{65}$. Si bien la finalidad recaudatoria se mantiene presente, pasa a un segundo plano, porque lo que se perseguirá con la regulación del tributo será alcanzar un determinado objetivo ${ }^{66}$. A nivel comparado, una de las principales causas por las cuales el fenómeno de la extrafiscalidad se ha acrecentado radica, precisamente, en la preocupación por el medio ambiente ${ }^{67}$.

Ahora bien, es necesario distinguir entre tributos que son genuinamente

${ }^{63}$ García Novoa, César, El concepto de tributo (Madrid, Marcial Pons, 2012), pp. 207-209.

${ }^{64}$ Fernández González, Miguel Ángel, Principios constitucionales de proporcionalidad y justicia en materia tributaria, en Revista Chilena de Derecho 27 (2002), 2, p. 357. De hecho, Masbernat es consciente de la falta de desarrollo dogmático de este principio e intenta construirlo tomando como base la normativa española. Masbernat, Patricio, Reglas y principios de justicia tributaria: Aportes del Derecho español al Derecho comparado, en Revista de Derecho de la Universidad Católica del Norte 20 (2013), 1, pp. 156-159.

${ }^{65}$ VARONA, cit. (n. 62), p. 23.

${ }^{66}$ Como expresa Domingues, la recaudación del impuesto ambiental, tributo por antonomasia extrafiscal, debe ser siempre tan secundaria y efímera como indeseable, pues frustra el objetivo consistente en el cambio en la actitud contaminante. Domingues, José Marco, Tributos Medioambientales en Brasil: una perspectiva comparada con España, en Quincena Fiscal 22 (2011), p. 9, BIB 2011\1808.

${ }^{67}$ VArONA, cit. (n. 62), p. 11. 
recaudatorios, pero que tienen elementos extrafiscales ajenos a esta finalidad, de aquellos otros que tienen un fundamento y estructura concebida para lograr un objetivo de carácter extrafiscal. Solo estos últimos pueden calificarse como tributos propiamente fiscales. Dentro de sus notas definitorias está el hecho de que persiga una finalidad extrafiscal y que el factor extrafiscal esté presente en sus elementos esenciales, de forma tal que la carga tributaria se module en función del fin extrafiscal; asimismo, ha de fomentar conductas acordes con la finalidad perseguida, aumentando el gravamen cuando se verifican conductas indeseadas y reduciéndola cuando muestre una actitud que favorezca el logro del objetivo ${ }^{68}$.

La idea de Pigou de que se internalizase el costo de la contaminación, como externalidad negativa, mediante un tributo fue recogida en la expresión quien contamina paga, la que está a la base de la regulación de un tributo ambiental y que vincula la temática tributaria con los principios del Derecho ambiental.

El Derecho ambiental reconoce la importancia del principio preventivo ${ }^{69}$ y la estrecha vinculación que presenta con el principio quien contamina paga, pues si aquel atiende a determinar cuándo deben adoptarse medidas de protección ambiental, este precisa quién debe soportar los costos de tales medidas ${ }^{70}$. En el fondo, el promotor de toda actividad o proyecto sea de carácter público o privado, tiene la obligación de internalizar las

${ }^{68}$ VARONA, cit. (n. 62), pp. 28-30. En Chile, la nomenclatura que usa la doctrina es diversa, pero tiene el mismo fundamento, ya que se distingue entre tributo ambiental impuro y tributo ambiental puro. Véase Matus, cit. (n. 5), p. 1038. Si se examina la legislación tributaria, es posible constatar que existe una finalidad medioambiental en el impuesto a los combustibles, al tabaco y en el impuesto especial a la minería, por nombrar los más relevantes, pero su objetivo primordial es la recaudación por lo que no son tributos propiamente ambientales. Tampoco se puede desconocer que existen ciertos beneficios tributarios que tienden a proteger el medio ambiente, con lo cual incentivan la realización conductas más limpias, como ocurre con el crédito establecido en favor de las empresas constructoras que instalen sistemas solares términos en las viviendas que construyan, establecido por la Ley $\mathrm{N}^{\circ}$ 20.365 o la modificación proyectada por la ley de modernización a la legislación tributaria que en su artículo $2 \mathrm{~N}^{\circ} 13$, letra h) que permitiría rebajar como gasto en el impuesto de primera categoría los desembolsos derivados de la responsabilidad social empresarial en materia ambiental.

69 Según este, se pretende evitar o reducir los efectos negativos de carácter significativo sobre el entorno, ya que resulta más eficaz y eficiente para la gestión ambiental prever eventuales menoscabos o detrimentos que actuar una vez que estos ya se han producido. Astorga Jorquera, Eduardo, Derecho ambiental chileno. Parte General (5ª edición, Santiago, LegalPublishing, 2017), p. 14.

${ }^{70}$ Bermúdez, cit. (n. 7), p. 49. 
externalidades negativas de los mismos ${ }^{71}$. De esta manera, quienes generan los efectos adversos producidos por la actividad económica han de incluir en sus procesos elementos que permitan evitar o disminuir tales repercusiones $^{72}$.

\section{Tensiones constitucionales que generan los tributos ambientales}

Si se examina el tributo del artículo 8 de la ley, es claro que presenta una marcada finalidad extrafiscal, en concreto, de carácter ambiental, pues la cuantía de la obligación tributaria aumenta si se incrementa la cantidad de emisiones de contaminantes, y tendría más vigor aún, de aprobarse la compensación propuesta en la ley de modernización tributaria, que incorpora la posibilidad de compensar el impuesto.

Este tributo persigue alcanzar un objetivo constitucionalmente reconocido, como es, la protección del medio ambiente, según dispone el artículo $19 \mathrm{~N}^{\circ} 8$ de la Constitución ${ }^{73}$, que establece el deber constitucional de proteger el medio ambiente, y que puede devenir en reacciones concretas originadas en normas tributarias ${ }^{74}$.

Ahora bien, si se aborda la problemática ambiental desde ámbito tributario, es posible encontrar tensiones con los principios que rigen la potestad tributaria.

Una primera fricción que se presenta dice relación con la extrafiscalidad del tributo, pues se persigue cambiar comportamientos y no recaudar, con lo cual se encuentra en tensión el concepto mismo de tributo ${ }^{75}$.

El punto aún no ha sido resuelto en Chile por el intérprete constitucional, pero puede resultar ilustrativo recurrir al Derecho comparado para analizar cómo se solucionado esta problemática. En este sentido, los Tribunales Constitucionales de España, Italia y Alemania han reconocido el abandono de esa finalidad primordial de obtener ingresos no desnatura-

${ }^{71}$ Astorga, cit. (n. 69), p. 14.

72 GuZmán Rosen, Rodrigo, Derecho ambiental chileno: principios, instituciones, instrumentos de gestión (Santiago, Planeta Sostenible, 2012), pp. 91-92.

${ }^{73} \mathrm{La}$ disposición prescribe que la Constitución asegura a todas las personas: " 8 ..El derecho a vivir en un medio ambiente libre de contaminación. Es deber del Estado velar para que este derecho no sea afectado y tutelar la preservación de la naturaleza.

La ley podrá establecer restricciones especificas al ejercicio de determinados derechos o libertades para proteger el medio ambiente".

${ }^{74}$ Matus, cit. (n. 5), p. 1052.

${ }^{75}$ Este aspecto Varona, cit. (n. 62), p. 32, lo vincula con una fricción con el citado principio de capacidad contributiva, ya que la extrafiscalidad se contrapone a la fiscalidad: mientras más se consolide la finalidad extrafiscal, menos recaudación habrá. 
liza al impuesto ni lo convierte en una figura de otra especie ${ }^{76}$, ya que en este tipo de tributo la finalidad recaudatoria existe, pero no es principal.

Existe una segunda tensión constitucional que generan los tributos ambientales cuando se confronta ahora principio de capacidad económica con el principio quien contamina paga ${ }^{77}$, según el cual a través de los tributos deben gravarse manifestaciones de riquezas. Pese a que el principio de capacidad contributiva no se encuentra expresamente consagrado en la Constitución chilena, la doctrina lo desprende del principio de igualdad ${ }^{78}$.

En Chile el tema está planteado ${ }^{79}$, pero tal como el caso del punto anterior, tampoco existe una solución, por lo que nuevamente se puede acudir al Derecho comparado para hallar cuál ha sido la respuesta.

En España, por ejemplo, se reconoce que los tributos ambientales reducen el protagonismo del principio de capacidad contributiva, pero se afirma este no es el único fundamento ni la única medida de la carga tributaria ${ }^{80}$. El tema se zanjó por el Tribunal Constitucional español mediante la STC 37/1987, de 26 de marzo, fundamento jurídico 13, que declara que: "es constitucionalmente admisible que el Estado y las Comunidades Autónomas, en el ámbito de sus competencias, establezcan impuestos que, sin desconocer o contradecir el principio de capacidad económica o de pago, respondan principalmente a criterios económicos o sociales orientados al cumplimiento de fines o a la satisfacción de intereses públicos que la Constitución preconiza o garantiza. Basta que dicha capacidad económica exista, como riqueza o renta real o potencial en la generalidad de los supuestos contemplados por

${ }^{76}$ Véase García, cit. (n. 63), pp. 292-293 y 297, quien cita las sentencias del Tribunal Constitucional español 27/1981, de 20 de julio, fundamento jurídico 4 y 49/1984, de 5 de abril, fundamento jurídico 4, a la Corte Costituzionale italiana (clásicas Sentencias 49, de 1969, y 45, de 1968) y al Tribunal Constitucional alemán Bundesverfassungsgericht, en la importantísima Sentencia de 22 de mayo de 1963.

${ }^{77}$ Esta tensión la pone de realce Matus, cit. (n. 5), p. 1045, para quien el tributo ambiental si grava la emisión, no grava necesariamente una capacidad contributiva.

${ }^{78}$ SalaSSA BoIx, Rodolfo, Los tributos ambientales: la aplicación coordinada de los principios quien contamina paga y de capacidad contributiva, en Revista Chilena de Derecho 43 (2016), 4, pp. 1018 y 1023.

${ }^{79}$ Matus, cit. (n. 5), pp. 1046 y ss.

${ }^{80}$ Con todo, es necesario mencionar que PALAO es particularmente crítico respecto a la relevancia que se le ha dado al principio de capacidad económica y afirma que cuando se establecen tributos con fines extrafiscales, se prescinde de este principio como criterio de imposición y, en ocasiones, se actúa derechamente en su contra. A su juicio, si se eliminase el principio de capacidad contributiva no habría incidencia en los límites de las leyes fiscales ni en la precisión y determinación con que han de formularse. Palao TaBOADa, Carlos, Apogeo y crisis del principio de capacidad contributiva, en VV.AA, Estudios Jurídicos en homenaje al profesor Federico De Castro (Madrid, Editorial Tecnos, 1976), II, pp. 393 y 410 y ss. 
el legislador al crear el impuesto, para que el precepto constitucional quede a salvo" ${ }^{81-82}$. Para admitir la legitimidad de este tipo de gravámenes, en España se señala que es necesario que cumplan con exigencias propias del principio de proporcionalidad, a través del cual se realiza el control de constitucionalidad. El tributo respetaría este principio si supera un triple test: i) idoneidad, en el sentido de que la medida debe ser adecuada para alcanzar su fin; ii) necesariedad, que suponga el mínimo sacrificio a igualdad de costes para obtener el objetivo deseado, y iii) proporcionalidad en el sentido estricto, esto es, un equilibrio entre la restricción de derechos y los efectos positivos que alcanzan ${ }^{83}$.

\section{Problemas aplicativos del impuesto Que grava las emisiones De} FUENTES FIJAS

\section{Problemas en la determinación de la base imponible}

La base imponible es la unidad de medida del tributo, esto es, la suma de dinero, bien o entidad abstracta sobre la cual debe aplicarse el tributo $^{84}$, y en virtud del principio de reserva legal tributaria, el Tribunal Constitucional chileno exige que la determinación de la base imponible se encuentre establecida en la ley ${ }^{85}$. De otra parte, la aplicación del principio de legalidad que rige a la Administración del Estado, para actuar, requiere que legalmente se establezca una determinada facultad.

${ }^{81}$ De esta forma, lo que se exige es que los tributos no desconozcan el principio de capacidad económica, y como afirma García, los tributos ambientales pueden "no estar inspirados exclusivamente en la misma por lo que la mera utilización del tributo con fines medioambientales no supone, por sí sola, una vulneración de las exigencias de capacidad económica mientras la misma esté presente como 'riqueza o renta real o potencial' [...]. Por ello, los tributos medioambientales suponen una salvedad en la necesaria concurrencia de capacidad económica”. GARCíA, cit. (n. 63), p. 297. SALASSA, cit. (n. 78), p. 1022, apunta a que no puede ser óbice para localizar la capacidad contributiva que subyace a un tributo ambiental, la circunstancia de que no siempre sea posible detectarla con claridad.

${ }^{82}$ Como apunta SAlassa, cit. (n. 78), pp. 1021-1022, para hablar de un tributo ambiental, su estructura debe responder al criterio de la capacidad contaminante del sujeto pasivo.

${ }^{83}$ Herrera Molina, Pedro, Derecho tributario ambiental: la introducción del interés ambiental en el ordenamiento tributario (Madrid, Marcial Pons, 2000), p. 29.

${ }^{84}$ Aste Mejías, Christian, Curso sobre derecho y código tributario (7a edición, Santiago, Thomson Reuter, 2016), p. 185.

${ }^{85}$ STC Roles Nos $718-2007$, de 26 de noviembre de 2007 , considerandos $18^{\circ}$ y $19^{\circ}$; 822-2007, de 13 de noviembre de 2007, considerando $5^{\circ}$; 1234-2008, de 7 de julio de 2009 , considerando $21^{\circ}$; 2038-2011, de 31 de enero de 2013, considerando $17^{\circ}$, y 3.361-2017, de 5 de abril de 2018, considerando $8^{\circ}$. 
En este escenario, cabe señalar que la regulación del artículo 8 de la ley es deficitaria, por cuanto no establece la forma como se puede precisar la base imponible si el contribuyente no reporta las emisiones a la SMA. Es más, la ley tampoco contempla la posibilidad de que la autoridad pueda modificar los valores reportados por el obligado tributario si se determina que lo informado no se corresponde con la realidad.

La SMA consciente de este problema, intentó remediar la situación indicando la forma en que se debía determinar las emisiones frente al incumplimiento de la obligación de reporte de las emisiones por parte del contribuyente, a través del instructivo para la cuantificación de las emisiones de fuentes fijas afectas al impuesto del artículo 8 de la ley, aprobado por la Resolución Exenta SMA N ${ }^{\circ} 1053,2016^{86}$; no obstante ello, la instrucción fue modificada y la actualmente vigente, contenida en el instructivo aprobado por la citada Res. Ex. SMA N 55, de 2018, eliminó tal instrucción.

El cambio parece acertado, ya que la autoridad ambiental no tiene competencias para determinar la base imponible del impuesto. En efecto, cabe señalar que el artículo $8^{\circ}$ de la ley precisa que se pueden estimar las emisiones, cuando dispone que la SMA: "podrá definir los requerimientos minimos de operación, control de calidad y aseguramiento de los sistemas de monitoreo o estimación de emisiones". Sin embargo, no le da la facultad a tal organismo para determinar autónomamente las emisiones, sino que se refiere a que puede contemplar como sistema de medición de emisiones de los contribuyentes la estimación de las mismas, lo que es diverso a que la autoridad sea quien determine cuánto emitió el contribuyente lo que, en definitiva, redunda en una estimación de la base imponible.

Pese a que legalmente la SMA tiene labores de verificación, es a través de una instrucción administrativa que dicha entidad precisa que tales funciones permiten verificar la metodología de cuantificación, la condiciones de medición, muestreo y/o estimación y la información reportada. Respecto a este último punto, el instructivo señala que como acciones generales se deberá realizar dos cruces de la información reportada: a) con variables operacionales informadas adicionalmente y/o con datos históricos, y b) con

${ }^{86}$ En su punto 9, instruía que la metodología de cuantificación de las emisiones se entiende única para todo el año calendario, de forma tal que "si el establecimiento reporta parcialmente o no reporta las emisiones del período (año calendario), de acuerdo a la metodología aprobada, esta Superintendencia realizará una estimación de la emisión para el período completo (todo el año calendario), asumiendo funcionamiento continuo a plena carga, consumo máximo de combustible de acuerdo a las condiciones de diseño y no existencia de sistemas de abatimiento". 
otros organismos públicos y/o privados, que puedan proveer información útil para complementar el proceso de verificación.

Se considera que la SMA perfectamente podría determinar que hay errores en el reporte de la información, pero en tal caso solo puede imponer una multa por el incumplimiento, sin que se estime procedente que realice la determinación correcta de las toneladas de contaminantes emitidos al aire, ya que esto supone tasar la base imponible, careciendo de competencias para ello. En esta línea, si se tiene presente que en materia impositiva rige el principio de legalidad del tributo, y que la base imponible es un elemento del mismo que necesariamente debe estar establecido por ley, mal podría la SMA precisar este valor y remitirlo al SII.

Por su parte, las competencias del SII no permiten solucionar la hipótesis propuesta, esto es, que el contribuyente no reporte o lo haga de manera indebida, ya que las normas de tasación están pensadas para supuestos en que la Administración tributaria realiza un análisis de la contabilidad del contribuyente, lo que no ocurre en este caso. Es más, expresamente dicha Administración tributaria ha señalado que en el citado Oficio SII $N^{\circ} 1605$ que: "como se aprecia, el legislador expresamente ha conferido a este Servicio un muy limitado ámbito de competencia, que se reduce al mero cálculo del impuesto en base a la información proporcionada por otros Órganos de la Administración del Estado, sin que corresponda a este Servicio ninguna atribución legal o técnica para revisar, validar o interpretar cómo se construyen los datos informados para el cálculo del impuesto por cada fuente emisora".

El punto es sumamente relevante, pese a lo cual la reforma tributaria del Gobierno no incluye ninguna norma que solucione este problema. No debe se perder de vista que al tratarse de un impuesto de giro -y no de declaración por parte del contribuyente-, la obligación tributaria prescribe a los tres años contados desde la expiración del plazo legal en el que debió efectuarse el pago. De esta forma, a falta de reporte del contribuyente de sus emisiones, la autoridad tendrá solo un plazo de tres años para determinar la obligación tributaria y emitir el correspondiente acto administrativo, ya que de lo contrario, como señala la Circular del SII No 73, de 2001, prescribirá la facultad de la autoridad para revisar y girar los impuestos respectivos. 


\section{El devengo del tributo y el incumplimiento de la norma de emisión}

Otro problema aplicativo que se puede presentar, y que tempranamente fue identificado por Mateluna ${ }^{87}$, se refiere a si produce algún efecto tributario el incumplimiento de las normas de emisión ${ }^{88}$.

Desde un punto de vista administrativo ambiental, esta situación da lugar al ejercicio de la potestad sancionatoria de la autoridad por incumplimiento de lo establecido en un instrumento jurídico de protección ambiental. En efecto, se afirma en doctrina que el control directo de la contaminación se efectúa a través de instrumentos propios del Derecho administrativo ambiental. Su incumplimiento genera, entre otras sanciones, una multa, la que puede ser considerada por los contaminadores como un tipo de precios similar a impuestos o $\operatorname{cargas}^{89}$, aunque responden a una naturaleza diversa.

La problemática que surge en este punto se refiere a si han de tributar las emisiones de contaminantes que exceden la norma de emisión. La hipótesis presupone que las emisiones tuvieron lugar, por lo que en principio debiera afirmarse que el hecho gravado se realizó y, consecuentemente, surgió la obligación tributaria; sin embargo, estas habrían tenido lugar por sobre las cantidades aceptadas en el instrumento jurídico de protección ambiental, por lo que la actividad no es lícita, en el sentido de que no es admitida por el derecho. En el fondo, lo que está detrás de la problemática señalada se refiere a si las actividades ilícitas, en el sentido de no admitidas por el derecho, deben tributar.

La solución en este caso no es tan simple como cuando la ilicitud tiene lugar en sede civil. Piénsese, por ejemplo, en que hay un contrato que adolece de un vicio de nulidad y que un juez civil la declara por sentencia firme. El efecto propio de la nulidad, por regla general, es la retroactividad, con lo cual la consecuencia que se genera es que el contrato nunca nació a la vida del derecho. De ello se sigue que si con la celebración o ejecución del contrato anulado judicialmente se verificó el presupuesto de hecho de una norma tributaria, y nació la obligación tributaria, esta también desa-

${ }^{87}$ Mateluna, cit. (n. 4).

${ }^{88}$ Artículo 2 letra o) de la Ley de Bases Generales del Medio Ambiente prescribe que son "las que establecen la cantidad máxima permitida para un contaminante medida en el efluente de la fuente emisora". Esto es, la determinación de una cantidad de contaminante, que puede ser medido o valorado en el efluente -lugar o punto desde el que fluye, emana o se emite un contaminante- de la fuente emisora. BERMÚDEZ, cit. (n. 7), p. 228.

${ }^{99}$ Yábar Sterling, Ana, Impuestos versus controles directos, en Ella misma (dir.), La protección del medio ambiente. Aspectos económicos y jurídicos (Madrid, Marcial Pons, 2002), pp. 159-160. 
parece, por lo que quien enteró indebidamente dineros en arcas fiscales puede solicitar su devolución.

La hipótesis que se analiza tiene un componente diverso, ya que las emisiones efectuadas por sobre lo admitido no pueden retrotraerse, $y$ generan un doble efecto: de una parte un incumplimiento sancionable desde la perspectiva del Derecho administrativo sancionador $y$, de otra, se verifica un hecho gravado, que hace surgir la obligación tributaria, con la consecuente obligación de pago. En Chile la doctrina pareciera decantarse por señalar que solo pueden tributar las actividades lícitas, por lo que en casos como el descrito no podría surgir la obligación tributaria ${ }^{90}$, y a nivel comparado parecieran ser escasas las posturas que favorables a admitir el devengo del tributo ${ }^{91}$.

Lo central pareciera ser que el instrumento económico de protección ambiental debe actuar coordinadamente con los restantes mecanismos de protección ambiental, de forma tal que solo se graven las emisiones permitidas. Sin embargo, no es claro que la ley opte por esta solución, ni tampoco parece que las autoridades involucradas hayan detectado esta problemática.

\section{Finalidad ambiental del tributo y el principio de no afectación tributaria}

Pese a que estrictamente hablando el tema planteado no es propiamente aplicativo, su desarrollo se efectuará en este apartado, pues su solución implicaría necesariamente una reforma constitucional.

Parece lógico que si se establece un tributo ambiental lo recaudado por este gravamen sea destinado, al menos en parte, al desarrollo de políticas públicas para combatir la contaminación o contrarrestar sus efectos en el lugar donde las emisiones tuvieron lugar. Ocurre, sin embargo, que respecto del tributo ambiental establecido en el artículo 8 de la ley, no se establece ningún tipo de afectación especial de lo recaudado con el tributo, con lo cual, estos ingresos públicos van a las arcas generales de la nación. Rige, a este respecto, íntegramente lo prescrito en el inciso 3 del artículo $19 N^{\circ} 20$ de la Constitución, según el cual: "los tributos que se recauden,

${ }^{90}$ Mateluna, cit. (n. 4), pp. 21, 25, 39 y 42-43. También Matus, para quien el tributo ambiental está dirigido a operar dentro de los límites de alteración o impacto ambiente permitidos o tolerados por el legislador, con el objeto de establecer estímulos para que la actividad se desarrolle de la forma más respetuosa posible con el ambiente. Matus, cit. (n. 5), p. 1045. En España es de esta postura Herrera, cit. (n. 83), p. 64.

${ }^{91}$ Hasta donde conocemos, Messerschmidt, citado por Herrera, cit. (n. 83), pp. 64-65. 
cualquiera que sea su naturaleza, ingresarán al patrimonio de la Nación y no podrán estar afectos a un destino determinado".

La CEPAL y la OCDE vieron en esta norma constitucional una limitación a las iniciativas hacia la aplicación de la tributación ambiental ${ }^{92}$. A la luz de la inclusión de tributos ambientales se puede constatar que la regla constitucional no fue un impedimento para avanzar hacia la protección del medio ambiente empleando la herramienta fiscal.

Sin embargo, no se ve motivo para mantener el sistema actual y, en cambio, parecen haber razones de política ambiental que hacen aconsejable destinar una parte de lo recaudado a los lugares donde la contaminación se produjo, con el fin de mitigar sus efectos ${ }^{93}$. Es más, la Constitución en el inciso 4 del artículo $19 \mathrm{~N}^{\circ} 20$ prescribe que la ley podrá autorizar que los tributos "que gravan actividades o bienes que tengan una clara identificación regional o local puedan ser aplicados, dentro de los marcos que la misma ley señale, por las autoridades regionales o comunales para el financiamiento de obras de desarrollo". Si se examina la disposición, no parece posible que lo recaudado por el impuesto del artículo 8 de la ley pueda ser aplicado a políticas ambientales que busquen prevenir o contrarrestar los efectos de la contaminación, toda vez que es discutible que estas se encuadren dentro de la expresión "obras de desarrollo" que utiliza la Constitución ${ }^{94}$, la que más bien apuntaría al "financiamiento de obras de infraestructura, de ingeniera,

${ }^{92}$ CEPAL - OCDE, cit. (n. 9), p. 136.

${ }^{93}$ Punto que, por lo demás, se planteó en la discusión parlamentaria de la Ley $\mathrm{N}^{\circ}$ 20.780. Coronado, cit. (n. 13), pp. 21 y 45.

${ }^{94}$ Recientemente, la Ley $\mathrm{N}^{\circ} 21.078$ establece un gravamen que se aplica al mayor valor generado en la enajenación de bienes raíces producto de la ampliación del límite urbano. Las sumas que la Tesorería recauda por este concepto, las pondrá a disposición de las respectivas Municipalidades y del Fondo Común Municipal, ya que según dispone el artículo 12 de la citada ley, lo recaudado por este tributo se distribuirá de la siguiente manera: “a) Un 37,5\% se incorporará al patrimonio de la municipalidad correspondiente a la comuna en que se encuentre situado el respectivo bien raíz, para ser aplicado por la autoridad comunal al financiamiento de obras de desarrollo local. Si el bien raíz se encuentra situado en varias comunas, la recaudación se repartirá entre ellas en proporción a la parte de la superficie total que corresponda a cada una.

b) Un $62,5 \%$ se incorporará al patrimonio del Fondo Común Municipal establecido en el artículo 14 de la ley $\mathrm{N}^{\circ}$ 18.695, orgánica constitucional de Municipalidades, cuyo texto refundido, coordinado y sistematizado fue fijado por el decreto con fuerza de ley $\mathrm{N}^{\circ} 1$, de 2006, del Ministerio del Interior". El porcentaje de recaudación destinado a las Municipalidades expresamente se vincula a "obras de desarrollo local”. 
o de un contenido semejante, lo que sin duda limita la posibilidad para el legislador de aprobar leyes tributaria regionales" 95 .

La experiencia de lo ocurrido en Quintero y Puchuncaví puede dar buena cuenta de los estragos que la contaminación atmosférica causa en la salud de la población que vive en los lugares donde se emiten los contaminantes gravados con este impuesto y de lo importante que es contar con recursos para prevenir este tipo de emergencias generadas por la contaminación ambiental y reaccionar frente a episodios generados por ella.

\section{CONCLUSIONes}

La Ley $\mathrm{N}^{\circ} 20.780$ incorpora dos tributos ambientales a la legislación impositiva chilena en sus artículos 3 y 8 , en respuesta a las recomendaciones formuladas por la CEPAL y la OCDE en la Evaluación de Desempeño Ambiental que efectuaran a Chile en el año 2005. El documento señaló la necesidad de integrar consideraciones ambientales en los instrumentos y en la política fiscal, para mejorar el desempeño ambiental y avanzar hacia un desarrollo sustentable.

El cambio apuntado incluye a los tributos ambientales o pigouvianos como una de las herramientas económicas de protección ambiental, haciendo realidad en materia tributaria el principio quien contamina paga. La característica de estos impuestos consiste en que si bien no prohíben la realización de conductas contaminantes, introducen un gravamen que busca internalizar los costos de la contaminación, con lo cual, indirectamente, se desincentivan las conductas contaminantes y se motiva el cambio hacia soluciones más limpias.

El tributo del artículo 8 de la ley establece un gravamen a las emisiones al aire de ciertos contaminantes emitidas por ciertas fuentes fijas, que tiene una tasa diferenciada dependiendo, en primer lugar, del contaminante medido y, en segundo lugar, respecto de los contaminantes diversos al $\mathrm{CO}_{2}$, según si la comuna donde se encuentra ubicada la fuente fija ha sido declarada o no zona saturada o latente. Pese a que no existe un mínimo exento, respecto de las emisiones de $\mathrm{CO}_{2}$, se contempla una exención cuando las fuentes fijas operen en base a medios de generación renovable no convencional cuya fuente de energía primaria sea la energía biomasa.

En el año 2016, Chile nuevamente es evaluado en su desempeño ambiental por la CEPAL y la OCDE, organismos que reconocen el avance

${ }^{95}$ Mensaje del proyecto de ley sobre descentralización financiera y tributaria del Estado, Boletín N 12.126-07, disponible [en línea]: https://www.camara.cl/pley/ pley_detalle.aspx?prmID $=12647 \&$ prmBoletin $=12126-07]$, p. 5, presentado a través de una moción parlamentaria el día 26 de septiembre de 2018. 
que supone introducir en Chile un impuesto que grave las emisiones de contaminantes al aire de fuentes fijas, pero que critican ciertos aspectos concretos de su configuración legal. Las modificaciones que contempla el proyecto de ley que moderniza la legislación tributaria, en buena parte, son una respuesta a las críticas planteadas en esta última evaluación.

Pese a lo positivo que implica que en Chile se establezca un tributo, como el analizado, con una finalidad que claramente pretende proteger el medio ambiente, es necesario determinar si su estructura se adecúa al sistema tributario chileno. En efecto, el impuesto presenta una estructura extrafiscal, pues la cuantía de la obligación tributaria aumentará según se incrementen las emisiones de contaminantes a la atmósfera y disminuirá, cuando ellas decrezcan. En este, la finalidad recaudatoria es secundaria: lo buscado es obtener un cambio en la conducta contaminante. Esta característica del impuesto ambiental genera tensiones con los principios constitucionales que rigen la potestad tributaria, en primer lugar, respecto al concepto mismo de tributo, porque lo esencial a este es allegar recursos para que el Estado promueva el bien común; en segundo lugar, con el principio de capacidad contributiva, pues el gravamen no se establece teniendo en consideración una manifestación de riqueza.

Ahora bien, cabe señalar que a nivel comparado estas problemáticas se encuentran resueltas, pues se asume por los intérpretes de la Constitución que la finalidad recaudatoria no es exclusiva en el tributo y que el abandono de esa finalidad primordial de obtener ingresos no desnaturaliza a los impuestos ni los convierte en figuras de otra especie. Asimismo, respecto a las tensiones con el principio de capacidad económica, se afirma que basta con que exista una capacidad económica, como riqueza o renta real o potencial, para cumplir con las exigencias de tal principio.

Finalmente, el impuesto presenta problemas aplicativos que la reforma tributaria no soluciona y respecto de los cuales es imprescindible encontrar una respuesta: i) cómo determinar la base imponible si el contribuyente no reporta sus emisiones o lo hace erróneamente; ii) especificar si las emisiones que infringen la norma de emisión deben o no ser sometidas a tributación; y iii) afectar específicamente la recaudación de este tributo al desarrollo de aspectos propios de una política ambiental para las zonas en las que la contaminación tiene lugar. 


\section{BiBLIOGRAFÍA}

Aste MejíAs, Christian, Curso sobre derecho y código tributario (7a edición, Santiago, Thomson Reuter, 2016).

Astorga Jorquera, Eduardo, Derecho ambiental chileno. Parte General (5a edición, Santiago, LegalPublishing, 2017).

Bermúdez Soto, Jorge, Fundamentos de Derecho ambiental (2a edición, Valparaíso, Ediciones Universitarias de Valparaíso, 2014).

CEPAL - OCDE, Evaluaciones del desempeño ambiental. Chile 2005 (Santiago, CEPAL, 2005).

CEPAL - OCDE, Evaluaciones del desempeño ambiental. Chile 2016 (Santiago, CEPAL, 2016).

Contreras Rojas, María José - Pinochet Abalos, María Jesús, Análisis comparado del impuesto chileno a las emisiones de contaminantes provenientes de fuentes fijas a la luz de la normativa española, en Crónica Tributaria 165 (2017).

Coronado Lagos, Evelyn, Impuesto chileno sobre emisiones a la atmósfera provenientes de fuentes fijas. (Un estudio a la luz de la legislación española) (Madrid, Instituto de Estudios Fiscales, 2016).

Domingues, José Marco, Tributos Medioambientales en Brasil: una perspectiva comparada con España, en Quincena Fiscal 22 (2011).

Esteve Pardo, José, Derecho del medio ambiente (3a edición, Madrid, Marcial Pons, 2014).

Faúndez Ugalde, Antonio - Dalri Timm do Valle, Mauricio, Hacia una nueva normativa tributaria de protección del medio ambiente: la experiencia comparada en el Derecho tributario brasileño, en Revista de Estudios Tributarios 10 (2014).

FernÁndez GonZÁlez, Miguel Ángel, Principios constitucionales de proporcionalidady justicia en materia tributaria, en Revista Chilena de Derecho 27 (2002), 2.

García Novoa, César, El Reglamento del impuesto gallego sobre Contaminación Atmosférica. Puntualizaciones a la Sentencia del TSJ de Galicia de 3 de julio de 2001, en Repertorio de Jurisprudencia 33 (2002).

García Novoa, César, El concepto de tributo (Madrid, Marcial Pons, 2012).

GuZMÁn Rosen, Rodrigo, Derecho ambiental chileno: principios, instituciones, instrumentos de gestión (Santiago, Planeta Sostenible, 2012).

Herrera Molina, Pedro, Derecho tributario ambiental: la introducción del interés ambiental en el ordenamiento tributario (Madrid, Marcial Pons, 2000).

Masbernat, Patricio, Reglas y principios de justicia tributaria: Aportes del Derecho español al Derecho comparado, en Revista de Derecho de la Universidad Católica del Norte 20 (2013), 1.

Massone Parodi, Pedro, Principios de Derecho Tributario (4a edición, Santiago, LegalPublishing, 2016), II.

Mateluna Pérez, Rodrigo, Derecho tributario y medio ambiente. La posibilidad constitucional de establecer tributos ambientales en Chile (Santiago, LexisNexis, 2005).

Matus Fuentes, Marcelo, Particularismos e imposibilidades de los impuestos a las emisiones en la Constitución Politica de Chile. Estudio preliminar, en Revista Chilena de Derecho 42 (2015), 3.

Palao Taboada, Carlos, Apogeo y crisis del principio de capacidad contributiva, en VV.AA, Estudios Jurídicos en homenaje al profesor Federico De Castro (Madrid, Editorial Tecnos, 1976), II. 
Rozas Valdés, José Andrés, Riesgo de contaminar y tributos autonómicos, en Quincena Fiscal 2 (2006).

SALASSA BOIX, Rodolfo, La protección ambiental a través de los tributos en el marco de la relación entre el deber de contribuir y el deber de preservar el medio ambiente, en Quincena Fiscal 12 (2018).

SALASSA BoIX, Rodolfo, Los tributos ambientales: la aplicación coordinada de los principios quien contamina paga y de capacidad contributiva, en Revista Chilena de Derecho 43 (2016). 4.

Varona Alabern, Juan Enrique, Extrafiscalidad y dogmática tributaria (Madrid, Marcial Pons, 2009).

Yábar Sterling, Ana, La temática ambiental en las doctrinas económicas del siglo XX. Introducción y aspectos generales, en ElLA Misma (dir.), La protección del medio ambiente. Aspectos económicos y jurídicos (Madrid, Marcial Pons, 2002).

YÁbar Sterling, Ana, Impuestos versus controles directos, ahora, en Ella Misma (dir.), La protección del medio ambiente. Aspectos económicos y jurídicos (Madrid, Marcial Pons, 2002). 